\title{
Benign mesenchymoma of the stomach
}

\author{
MT HAQQANI, N KRASNER, ${ }^{*}$ M ASHWORTH \\ From the Departments of Histopathology and *Medicine, Walton Hospital, Liverpool L9 $1 A E$
}

SUMMARY Benign mesenchymoma is a mixed tumour of mesenchymal derivatives composed of $\overrightarrow{\mathbb{P}}$ mixture of two or more mesenchymal elements in addition to fibrous tissue. Two cases of this tumour of the stomach are reported. As far as can be ascertained, there has been no previoug report of gastric mesenchymoma.

Tumours derived from mesenchymal tissues of the stomach-for example, leiomyoma, lipoma, neurofibroma, etc, have been extensively recorded. Mesenchymoma of the stomach has not been described previously. The term "mesenchymoma" was first described by Klein ${ }^{1}$ in 1932, the term was used by Tauber ${ }^{2}$ in 1938 and Gilmour ${ }^{3}$ in 1943 described a benign recurring tumour of the back composed of embryonic connective tissue which he suggested could be called a mesenchymoma. Stout ${ }^{4}$ in 1948 established mesenchymoma as a distinct tumour entity and defined it as a tumour composed of two or more mesenchymal derivatives in addition to fibrous tissue. He recognised a benign form capable of recurrence and a malignant form capable of metastasis. Symmers and Nangle 5 in 1951 reserved the term mesenchymoma for neoplasms composed of more than one type of connective tissue and found these tumours to be locally malignant, with recurrences tending to be more cellular and less well differentiated. Since then several studies have been published of benign and malignant mesenchymomata $^{6-11}$ to name a few. None of these studies refers to the origin of mesenchymoma from the stomach.

We report in this paper clinical and histopathological features of two cases of benign mesenchymomata of the stomach recently encountered in this hospital.

\section{Case reports}

CASE 1

A 78-year-old man who had previously enjoyed excellent health presented with a history of undue fatigue of several weeks duration. Clinically he was anaemic ( $\mathrm{Hb} 4.0 \mathrm{~g} / \mathrm{dl})$ with microcytic hypochromic

Accepted for publication 15 December 1982
RBC) and complained of a low grade pyrexia (37 $38^{\circ} \mathrm{C}$ ). He had slight bilateral ankle oedema and was normotensive but had a tachycardia of $108 / \mathrm{min}$. haemic systolic murmur was audible over the whole of praecordium and fine basal crepitations were apparent at both lung bases. A non-tender hepati婿 enlargement of $3 \mathrm{~cm}$ below the costal margin com: pleted the picture of mild congestive cardiac failure

The patient was transfused with six units of blood and commenced on Septrin for his pyrexia witb diuretics for oedema. His congestive cardiac failure resolved rapidly. A barium meal indicated a filling defect in the fundus of the stomach and a gastros copy confirmed the presence of a large submucosa tumour. Additional findings at gastroscopy were of $\overrightarrow{\vec{\theta}}$ small actively oozing superficial ulcer on the pylor ring, and a small hiatus hernia associated with mil reflux oesophagitis.

Despite his advanced years he was considered fit for surgery. At laparotomy the spleen was found to be enlarged and removed (weight $320 \mathrm{~g}$ ). The funda tumour was removed by local excision. The patient made an uneventful recovery and was discharged 19 days later. He remains well approximately foub years later.

\section{Pathology}

The gastric tumour consisted of two lobes, one measuring $4 \mathrm{~cm}$, the other $3.3 \mathrm{~cm}$ in diameter; they were attached to each other by a small bridge of similar tumour tissue measuring $0.5 \mathrm{~cm} \times 0.5 \mathrm{~cm}$ $0.3 \mathrm{~cm}$. Both nodules were smooth in outline and partially covered by gastric mucosa. There was no definite evidence of a capsule. The cut surface was similar in each of these nodules with a variegated pattern consisting of bands of fibrous tissue somes times arranged in whorls, areas of dense calcification and bone formation, some soft mucoid areas and fa

The spleen was enlarged (weight $320 \mathrm{~g}$ ) measur ing $14 \mathrm{~cm} \times 9 \mathrm{~cm} \times 3 \mathrm{~cm}$. The cut surface revealed 


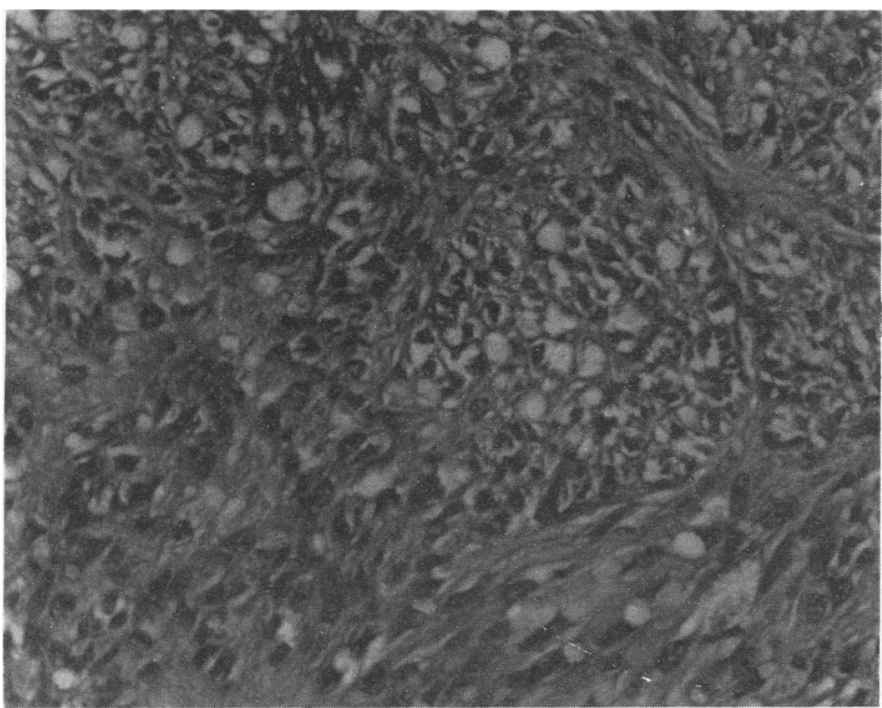

Fig. 1 Bands of spindle-shaped smooth muscle cells containing vacuoles of fat in the cytoplasm. Haematoxylin and eosin $\times 250$.

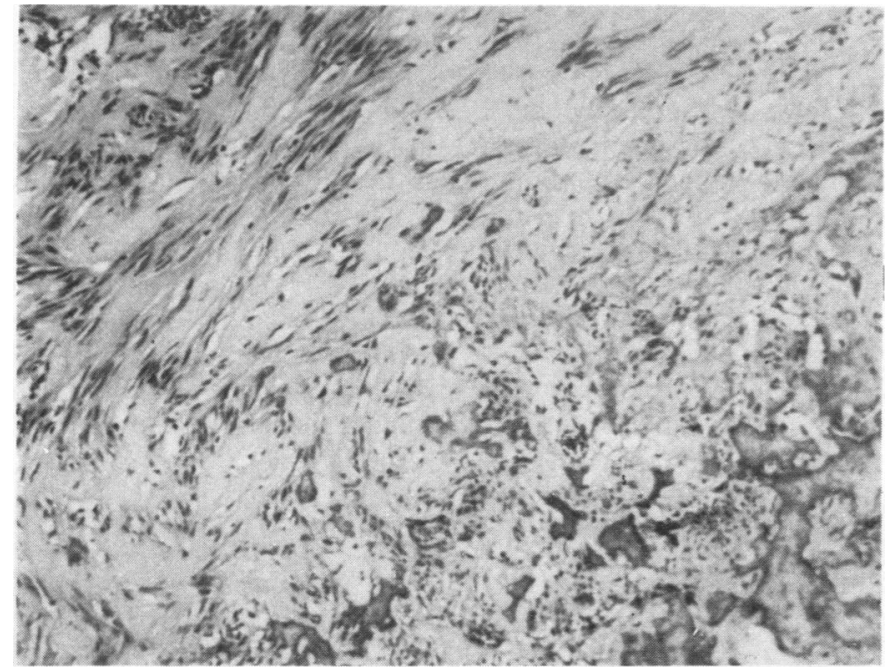

Fig. 2 Dense fibrous tissue, woven bone and cartilage-like areas. Haematoxylin and eosin $\times 125$.

no significant structural abnormality.

Histologically the gastric tumour was composed of proliferating bands of fibrous tissue alternating with smooth muscle fibres containing vacuolated cytoplasm (Fig. 1) which stained positively for fat. Heterologous tissue elements (Fig. 2)-for example, cartilage-like areas, osteoid, myxomatous tissue, fat and calcified areas with bone formation were found in both tumour nodules. The tumour was present in the submucosa and infiltrated the muscularis propria. The overlying muscularis mucosae and the mucosa were compressed. The bridge between the two nodules consisted almost entirely of fibrous and vascular tissue with smooth muscle containing vac- uolated cytoplasm. Since the tumour was composed of several mesenchymal tissues it was diagnosed as a mesenchymoma. The sections from the spleen revealed no significant cytological or structural abnormality.

\section{CASE 2}

A 71-year-old man was admitted with a history of intermittent dyspepsia and epigastric discomfort of 15 yr duration which was not related to food or posture. He had not lost any weight and was not anaemic. On examination the epigastrium was tender but no mass could be palpated. In 1970 he was investigated for dyspnoea when a barium meal had 
been reported as showing a sliding hiatus hernia only. The barium meal was repeated in 1978 and a lesion of the fundus of the stomach, possibly a neoplasm, was reported but a gastroscopy showed no abnormality other than mild chronic inflammation. One year later another barium meal suggested unusual appearance of the fundus but the gastroscopic biopsy showed mild non-specific chronic inflammation only. In December 1980 a doublecontrast barium meal showed a posterior wall fundal neoplasm and a gastroscopy confirmed an irregular mass on this occasion. In 1981 a mobile pedunculated tumour measuring $6 \mathrm{~cm} \times 4 \mathrm{~cm} \times 3 \mathrm{~cm}$, was removed from the posterior wall of the fundus, the remainder of the stomach was normal.

Postoperatively the patient developed a wound infection and a discharging sinus which subsequently resolved and was followed by ossification of the rectus sheath. The area of ossification was surgically removed in February 1982, a gastroscopy at this time showed the stomach to be normal. The patient has remained symptom-free since.

\section{Pathology}

The tumour mass appeared greyish white in colour, and well demarcated from the overlying mucosa. The cut surface was lobulated with a variegated appearance. There were dense fibrous-looking areas, foci of calcification, mucoid or myxomatous appearance and fat.

Microscopically the tumour was composed of spindle-shaped cells with vacuolated cytoplasm staining unevenly but positively for fat. Areas of myxomatous, fatty and pseudocartilaginous appear- ance were found with foci of calcification and os- $\frac{\vec{\nu}}{\overrightarrow{2}}$ sification. The smooth muscle and adipose tissue을 were confirmed by appropriate histochemical stain- $\overrightarrow{\vec{F}}$ ing. The vascularity of the tumour was markedly increased with some areas showing medium-sized? thick walled blood vessels in abundance. In places $\frac{\bar{F}}{5}$ loose vascular mesenchyme was separating islands $\vec{乛}$ of adipose tissue and smooth muscle cells containing $\varrho$ fat vacuoles (Fig. 3). No significant cellularos pleomorphism was noted and there was no evidence $\vec{\circ}$ of malignancy. The tumour mainly occupied the submucosa and either infiltrated or pushed the fibres $\vec{\omega}$ of muscularis propria. The overlying muscularis? mucosae and the mucosa were not infiltrated.

\section{Discussion}

Le Ber and Stout ${ }^{10}$ defined benign mesenchymoma as a tumour composed of two or more mesenchymal? elements not ordinarily found together in addition $\overrightarrow{-}$ to fibrous connective tissue. The prominent vascularo component of these lesions led Stout ${ }^{4}$ originally to conclude that benign mesenchymoma was a venous $\overrightarrow{0}$ haemangioma with connective tissue metaplasia. $\omega$ Eventually he decided that these were mixedo mesenchymal tumours with all connective tissue elements taking part in the growth. The terms angiomyolipoma, fibroblastoma, lipomyohaeman gioma, fibromyolipoma, haematoma and fibrolipoma have been used synonymously with benign mesenchymoma. Le Ber and Stout ${ }^{10}$ believe을 that such descriptive terms naming the mesenchymab components were unwieldly and it would be much simpler if the term benign mesenchymoma was used.

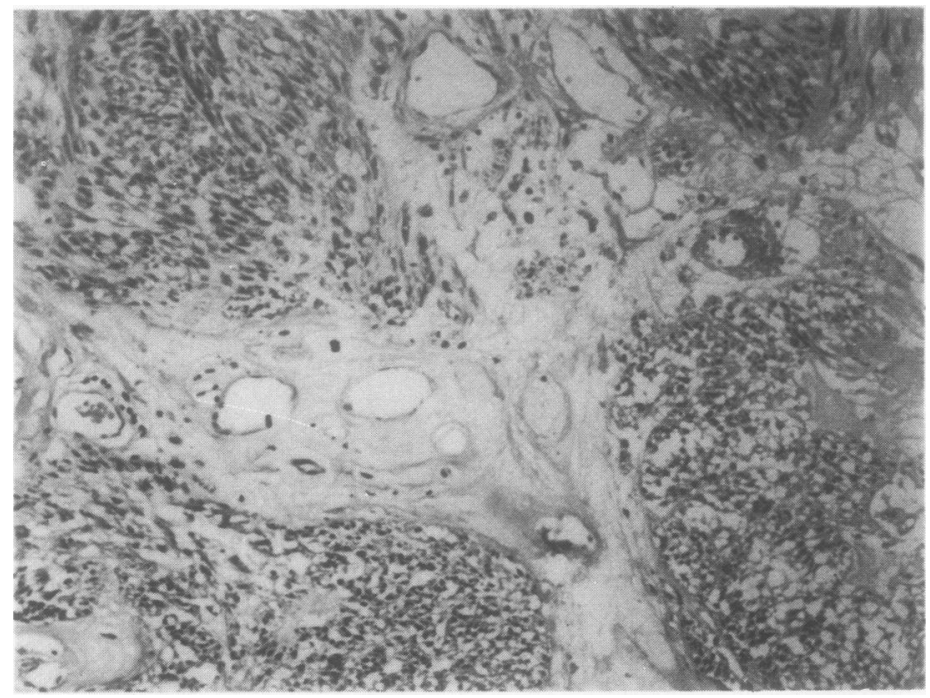

Fig. 3 Loose vascular mesenchyme, smoot muscle and fat. Haematoxylin and eosin $\times 125$. 
to describe these lesions. They also believed that these are unlikely to be hamartomas, a view discussed in detail by Bures and Barnes. ${ }^{\circ}$

In addition to fibrous tissue, a mixture of adult fat, blood vessels and smooth muscle, ${ }^{9}$ a typical benign mesenchymoma may contain other tissue-for example, cartilage, myxoid tissue, striated muscle, lymphoid tissue and haemopoietic tissue. ${ }^{11}$

The tumours described in this paper are remarkably similar and composed of an admixture of smooth muscle, fat, blood vessels, myxoid tissue, cartilage-like areas, osteoid and woven bone, in addition to fibrous tissue. These tumours were unencapsulated and appeared infiltrative which is consistent with most of the previously described cases of benign mesenchymomas. There was no significant pleomorphism, anaplasia or increased mitosis. Benign mesenchymoma is considered to be a separate entity from malignant mesenchymomas. These tumours may recur if incompletely excised. There have been no reported recurrences of benign mesenchymoma of the head and neck, but the follow-up times have been short. The suggested treatment of the lesions of the oral cavity is local excision. ${ }^{8}$ In sites other than oral cavity a recurrence is most often malignant and therefore should be treated aggressively. ${ }^{8}$ Clearly further studies with long-term follow-up are needed to determine the proper treatment and prognosis of benign mesenchymoma.

In our review of the world literature we were unable to find any report of mesenchymoma arising from the stomach. Both our cases are alive and well nearly four years and one-and-a-half years after operation.

\section{References}

${ }^{1}$ Klein W. Mesenchymoma. J Med Soc NJ 1932;29:774-8.

${ }^{2}$ Tauber EB, Goldman L, Barret C. Mesenchymoma, a new type of turban tumour. Archives of Dermatology and Syphilis 1938;37:444-50.

${ }^{3}$ Gilmour JR. A recurrent tumour of mesenchymoma in an adult. $J$ Pathol Bacteriol 1943;55:495-9.

${ }_{4}^{4}$ Stout AP. Mesenchymoma, the mixed tumour of mesenchymal derivatives. Ann Surg 1948;127:278-90.

${ }^{5}$ Symmers W St C, Nangle EJ. An unusual recurring tumour formed of connective tissue of embryonic type (so-called mesenchymoma). J Pathol Bacteriol 1951;63:417-28.

- Bures C, Barnes L. Benign mesenchymomas of the head and neck. Arch Pathol Lab Med 1978;102:237-41.

${ }^{7}$ Binns PM. Mesenchymoma of larynx and neck. Otolaryngal Head Neck Surg 1979;87:590-3.

${ }^{8}$ Januska J, Leban SG, Mashberg A. Mesenchymoma: A review of literature and report of two cases. J Surg Oncol 1976;8:22936.

' Bugg E, Mathews S. Benign mesenchymoma. South Med J 1970;63:268-73.

${ }^{10}$ Le Ber MS, Stout AP. Benign mesenchymoma in children. Cancer 1962;15:598-605.

"Freedman PD, Chou MD, Diner H, Lamerman H. Benign mesenchymoma of the oral soft tissues. Oral Surg 1982;53:606-10.

Requests for reprints to: Dr MT Haqqani, Department of Histopathology, Walton Hospital, Rice Lane, Liverpool L9 1AE, England. 